\title{
Perceived and Actual Knowledge of Cupping Therapy Concepts among Athletic Trainers in the State of Texas
}

ISSN: 2577-1914

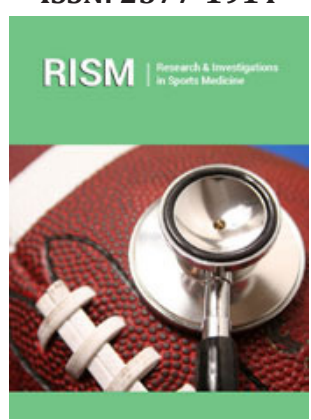

*Corresponding author: S Andrew C, University of Texas at Tyler, University of North Carolina, Greensboro, USA

Submission: 留 May 08, 2020

Published: 制June 30, 2020

Volume 6 - Issue 4

How to cite this article: S Andrew C, Brandon W, Diana G, Julie G, Winkelmann ZK. Perceived and Actual Knowledge of Cupping Therapy Concepts among Athletic Trainers in the State of Texas. Res Inves Sports Med, 6(4): RISM.000644. 2020 DOI: $10.31031 /$ RISM.2020.06.000644

Copyright@ S Andrew C, This article is distributed under the terms of the Creative Commons Attribution 4.0 International License, which permits unrestricted use and redistribution provided that the original author and source are credited.

\author{
S Andrew $\mathrm{C}^{1,2}$, Brandon $\mathrm{W}^{2,3}$, Diana $\mathrm{G}^{1}$, Julie $\mathrm{G}^{4}$ and Winkelmann $\mathrm{ZK}^{5}$ \\ ${ }^{1}$ University of Texas at Tyler, USA \\ ${ }^{2}$ University of North Carolina, Greensboro, USA \\ ${ }^{3}$ Grand Canyon University, USA \\ ${ }^{4}$ Collin College, USA \\ ${ }^{5}$ University of South Carolina, USA
}

\begin{abstract}
Recent studies have suggested a gap between perceived and actual knowledge of cupping therapy among athletic trainers. However, the authors of these studies have noted that further investigation into athletic training populations is needed to determine the full extent of this knowledge gap. Given that the majority of athletic trainers use cupping therapy to some degree in their clinical practice; this knowledge gap warrants further investigation. Thus, the purpose of this study was to determine the perceived and actual knowledge of cupping therapy among athletic trainers in the state of Texas. A total of 79 athletic trainers participated in this study (age $=34 \pm 12$ years, certified experience $=11 \pm 11$ years). Participants were sent an electronic survey by email that assessed frequency of usage, perceived knowledge, and actual knowledge of cupping therapy. Measures of central tendency (means, standard deviations, frequencies) were calculated for all survey items. Data was downloaded and analyzed using a commercially available statistics package (SPSS Version 26, IBM, Armonk, NY). A Pearson correlation was calculated for the perceived knowledge mean score and the actual knowledge total score to identify a knowledge gap between what participants believed they knew and what they actually knew. Lastly, an independent samples t-test was performed to assess the relationship difference in actual knowledge between those who had received education in cupping therapy and those who had not. The majority of athletic trainers agreed that cupping therapy was a necessary skill for their clinical practice. The majority of participants also reported using cupping therapy at least once during a typical week of clinical practice. Regarding perceived knowledge, the majority of participants were in the mid-range of agreement/disagreement, indicating at least some uncertainty about their knowledge of cupping therapy. Average scores on actual knowledge were $9.07 \pm 3.05$. A positive relationship was found between perceived knowledge and actual knowledge of cupping therapy $(\mathrm{r}=0.912, \mathrm{P}<0.001)$. Additionally, athletic trainers who had received some form of education in cupping therapy displayed significantly higher actual knowledge than those who had not received education $(p=0.003)$.As with previous studies, the majority of athletic trainers surveyed felt that cupping therapy was a necessary skill for their clinical practice. This continuously demonstrated knowledge gap between perceived and actual knowledge of cupping therapy suggests the need for future research on education regarding cupping therapy.
\end{abstract}

\section{Introduction}

Cupping therapy is a therapeutic modality that has been documented as early as $3300 \mathrm{BC}$ in ancient Macedonia [1]. By using different methods of suction, cupping therapy is utilized by clinicians around the world to improve blood flow, decrease pain, increase range of motion, and increase function [2-4]. Since the turn of the $21^{\text {st }}$ century, cupping therapy has grown in popularity in the United States and other countries where Western Medicine is practiced [1]. A large amount of this popularity is likely due to increased media interest resulting from elite level athletes receiving cupping therapy $[5,6]$. Although cupping therapy has increased in popularity as a treatment option in the United States, there is still no consensus on the ideal parameters for prescribing and applying cupping therapy to patients in an athletic population [1]. This lack of consensus may be due to a lack of high quality studies and a lack 
of standardized methodology [4,7]. Another potential factor may be advances in Western medicine that occurred during the 1900s [7].

There have been different theories regarding how cupping therapy achieves its therapeutic benefits. One potential method has been linked to the fact that cupping therapy has been shown to have a positive effect on local and regional blood flow $[3,8,9]$. During a cupping therapy treatment, the treated tissues undergo negative pressure that results in compression of the tissues in contact with the rim of the cup and distraction of the tissues within the cup. The amount of compression and distraction that occurs is determined by the amount of suction exerted by the cup. This lower pressure within the cup is suggested to cause a pressure differential between the skin within the cup and underlying capillaries [10]. When exposed to this change in pressure, blood vessels vasodilate, which causes localized increased blood flow at the treatment site [10]. This increase in blood flow may result in the pain reduction that has been achieved in previous studies [11]. Cupping therapy may also decrease pain through other mechanisms. Lowe suggested that while the body is healing the circular marks left by cupping therapy treatments, macrophages are attracted to the area and the enzyme heme oxygenase-1 (HO-1) is produced [11]. As the body breaks down HO-1, the bi products include: heme, biliverdin, bilirubin, carbon monoxide, and iron [11]. During this process, the iron is sequestered by ferritin and the other biproducts have direct and indirect effects that may create a better environment for healing at the treatment site [11].

Among athletic trainers, cupping therapy has grown in popularity in recent years. Researchers have begun examining the uses for cupping therapy for treating athletic populations [1]. In spite of this trend, there appears to only be one published study that has examined the prevalence of clinical use and the perceived and actual knowledge of cupping therapy among athletic trainers [12]. Further information on this topic would have potential value for athletic training educators attempting to prepare lessons or continuing education programs. The purpose of this study was to determine the perceived and actual knowledge of cupping therapy among athletic trainers in the state of Texas.

\section{Methods}

\section{Design}

This study was conducted using a cross-sectional design utilizing an internet-based survey for data collection.

\section{Participants}

Participants were recruited for this study by emailing head athletic trainers at colleges and universities in the state of Texas, as well as athletic trainers in local professional organizations in the state of Texas. A total of 79 participants (age $=34 \pm 12$ years, certified experience $=11 \pm 11$ years) opened the survey link and completed the instrument. Demographic information about the participants is presented in Table 1. All participants were informed of the survey's purpose as part of the beginning of the survey, at which point informed consent was obtained per the protocol approved by the University of Texas at Tyler Institutional Review Board.

Table 1: Totals and percentage for participant demographic information.

\begin{tabular}{|c|c|c|}
\hline \multirow{4}{*}{ Sex } & Criteria & Responses \\
\hline & Male & $30,50.6 \%$ \\
\cline { 2 - 3 } & Female & $39,49.4 \%$ \\
\hline \multirow{4}{*}{ Clinical Practice Setting } & College/University & $22,11.1 \%$ \\
\cline { 2 - 3 } & Secondary School & $6,3 \%$ \\
\cline { 2 - 3 } & Clinic/Hospital & $3,1.5 \%$ \\
\cline { 2 - 3 } & Professional Sports & $1,0.5 \%$ \\
\cline { 2 - 3 } & Emerging Settings & $17,8.6 \%$ \\
\hline \multirow{4}{*}{ Highest Degree Earned } & Professional Bachelor's & $32,16.2 \%$ \\
\cline { 2 - 3 } & Professional Master's & $10,5.1 \%$ \\
\cline { 2 - 3 } & Post-Professional Masters (in Athletic Training) & $16,8.1 \%$ \\
\cline { 2 - 3 } & Post-Professional Master's (not in Athletic & $3,1.5 \%$ \\
\cline { 2 - 3 } & Training) & $1,0.5 \%$ \\
\hline
\end{tabular}

\section{Data collection}

An email was sent to the head athletic trainers at the universities and colleges in the state of Texas, asking them to forward the email to their athletic training staff. The same email was also sent to the members of local athletic training organizations within the state of Texas. The message was then forwarded to all prospective participants inviting them to participate in an electronic survey via a hyperlink from a web-based server (Qualtrics Inc., Provo, UT) in May 2020. The inviting message contained information about the researchers, the purpose of the study, the nature of the survey, and assurances that the participants could opt to not complete the survey at any time. A follow-up email was sent to program directors a week after the initial email, and the survey was left open for a week prior to the survey being closed for statistical analysis. 


\section{Instrument}

After the informed consent and demographics section, the survey included questions addressing formal education and training regarding cupping therapy, as well as the frequency of usage for cupping therapy during typical clinical practice. Participants were also asked to provide information about the equipment they used to apply cupping therapy. The perceived knowledge questions were adapted from the Flynn and Goldsmith tool for perceived knowledge. Additionally, five questions were added addressing the participant's competency with prescribing and applying cupping therapy appropriately. Participants were given statements to read and then asked to answer using a scale from "strongly agree" (1) to "strongly disagree" (7).

To create the questions assessing actual knowledge of cupping therapy, a review of recent literature was performed to inform the content $[3,4,9]$. This content was designed to be similar to questions given to athletic training students in a therapeutic modalities class. These questions were developed by a researcher with content expertise and reviewed by a researcher with experience creating survey-based research. Ultimately, the survey consisted of 28 questions. These questions included: one question regarding informed consent, three multiple choice and two fill in the blank questions on demographics, six multiple choice and two multiple answer questions on education and current usage of cupping therapy, 10 Likert-scale items that assessed participants' perceived knowledge, and 10 multiple choice and two multiple answer questions that evaluated participants' actual knowledge.

\section{Statistical analysis}

Data from participant responses was downloaded and analyzed using a commercially-available statistics package (SPSS Version 26, IBM, Armonk, NY). 79 completed responses were included in the data analysis. Measures of central tendency (means, standard deviations, frequencies) were calculated where appropriate. The researchers reverse scored four items from the perceived knowledge portion of the questionnaire and calculated a mean score for the 10 items. Additionally, the researchers calculated a total correct score per participant on the actual knowledge assessment. A Pearson correlation was calculated for the perceived knowledge mean score and the actual knowledge total score to identify a knowledge gap between what participants believed the knew and what they actually knew. An independent samples t-test was calculated to assess the effects of receiving cupping therapy education on actual knowledge of cupping therapy. Significance was set at $\mathrm{P}<.05$ a priori.

\section{Results}

\section{Education}

The majority of athletic trainers stated that they had received some form of cupping therapy education, with67.1\% ( $n=53$ ) stating they had, and $32.9 \%(n=26)$ reporting they had not received education or instruction on the application of cupping therapy. For those who had undergone previous education, the most common forms included: peer-to-peer education $(60.4 \%, \mathrm{n}=32)$, personal experience such as reading text books and trial and error $(58.5 \%, \mathrm{n}$ $=31$ ), and continuing education through a company or organization (47.2\%, $n=25)$. The least common forms of knowledge transfer included: formal coursework in a post-professional program $(11.3 \%, \mathrm{n}=6)$ or video instruction $(22.6 \%, \mathrm{n}=12)$.

\section{Clinical usage}

Over half of participants $(59.5 \%, n=47)$ agreed that they felt cupping therapy was a necessary skill for their clinical practice. In contrast, $40.5 \%(n=22)$ felt the skill was not necessary. The participants were also asked to identify what supplies they most commonly utilized when completing cupping therapy. The majority of participants used plastic cups $(69.6 \%, \mathrm{n}=55)$ as compared to silicone $(49.4 \%, \mathrm{n}=39)$ or glass $(12.7 \%, \mathrm{n}=10)$ cups. Most participants reported using massage lotion $(46.8 \%, n=37)$ as their cupping therapy medium. The majority participants either reported to having used cupping therapy for patient care within the last six months $(15.7 \%, \mathrm{n}=31)$ or never $(10.6 \%, \mathrm{n}=10)$. The second finding suggested that $90.4 \%(n=69)$ of participants had used cupping therapy in patient care within the last year. The majority of athletic trainers reported using cupping therapy at least for at least one to three treatments during a typical week $(64.6 \%, n=51)$.

\section{Perceived knowledge}

The participants had a mean sum of the perceived knowledge items $(n=10)$ of $4.35 \pm 0.33$ out of 10 . This finding suggested that most participants were in the mid-range of perceived knowledge of cupping therapy. Frequency count of the most common correct responses is provided in Table 2 .

Table 2: Perceived Knowledge assessment most common response.

\begin{tabular}{|c|c|}
\hline Item & Most Common Response \\
\hline $\begin{array}{l}\text { I am comfortable with the different types of cupping therapy and what I can and cannot do as an athletic trainer } \\
\text { according to my state practice act. }\end{array}$ & Strongly Agree $(\mathrm{n}=29)$ \\
\hline $\begin{array}{c}\text { I do not feel very knowledgeable about the different techniques of cupping therapy including dry, wet, moving, flash, } \\
\text { herbal, and water cupping. }\end{array}$ & Somewhat Disagree $(\mathrm{n}=16)$ \\
\hline Around my colleagues, I would be considered an "expert" on cupping therapy. & Strongly Agree $(n=16)$ \\
\hline Compare to most athletic trainers, I know very little about cupping therapy. & Disagree $(n=19)$ \\
\hline I am able to explain the proposed mechanism of action for cupping therapy. & Agree $(n=37)$ \\
\hline $\begin{array}{l}\text { I understand what injuries are indicated and contraindicated, as well as when in the healing process it is appropriate } \\
\text { for cupping therapy as an intervention. }\end{array}$ & Strongly Agree $(n=27)$ \\
\hline I am unsure of how to perform function and safety inspections of cupping therapy equipment. & Disagree $(n=23)$ \\
\hline
\end{tabular}




\begin{tabular}{|c|c|}
\hline I am skilled and proficient in the application of cupping therapy. & Agree ( $\mathrm{n}=24)$ \\
\hline I am likely to pursue continuing education to improve my knowledge and skills about cupping therapy. & Strongly Agree (n=27) \\
\hline $\begin{array}{c}\text { I am unable to describe the physical sensation or patient experience of cupping therapy to a new patient undergoing } \\
\text { cupping therapy. }\end{array}$ & Disagree (n=31) \\
\hline
\end{tabular}

\section{Correlation between perceived and actual knowledge}

We identified a strong positive relationship between perceived knowledge mean scores and actual knowledge total correct sum scores $(r=0.912, P<.001)$. This suggested that as perceived knowledge of cupping therapy increased, actual knowledge of cupping therapy increased as well. The athletic trainers who reported having obtained cupping therapy education scored significantly higher with regards to actual knowledge than athletic trainers who had not received cupping therapy education (education, $10.85 \pm 1.34$, no education, $5.46 \pm 2.23$, $\mathrm{P}=0.003$ ).

\section{Discussion}

The purpose of this study was to assess the perceived and actual knowledge of cupping therapy concepts among certified and licensed athletic trainers in the state of Texas. A secondary purpose was to determine the frequency of usage of cupping therapy among these athletic trainers. Our findings suggest that over half of the athletic trainers surveyed believed cupping therapy was a necessary skill for their clinical practice $(59.5 \%, \mathrm{n}=47)$. Additionally, most of the participants reported using cupping therapy at least one to three times during a typical week $(64.6 \%, \mathrm{n}=51)$. Only $35.4 \%$ ( = 29) of athletic trainers surveyed reported never using cupping therapy. These findings indicate that athletic trainers are using cupping therapy with an increasing frequency and are beginning to view cupping therapy as a useful and necessary treatment technique.

While cupping therapy has grown increasingly popular in recent years, athletic trainers appear to be split with regard to their perceived knowledge of the modality [12]. Compared to a previous study that assessed actual knowledge of cupping therapy concepts among athletic trainers, the participants this study scored higher on average [12]. Furthermore, there was a positive relationship observed between perceived knowledge and actual knowledge of cupping therapy in this study. With further data analysis, it was found that athletic trainers who had received previous education on cupping therapy had significantly higher actual knowledge of cupping therapy concepts than individuals who had not received education. This finding indicates that education interventions are a crucial component to knowledge and skill acquisition among athlete trainers. Given the majority of participants reporting receiving education on cupping therapy, these findings suggest a need for emphasizing education on cupping therapy within athletic training curriculum and continuing education programming.

Previous studies have shown that clinical athletic training skills are subject to deterioration if they are not practiced over time $[12,13]$. Indeed, some studies have suggested that skills such as cardiopulmonary resuscitation can decrease in as little as six months [13]. On average, athletic trainers are more likely to use cupping therapy on a weekly basis compared to cardiopulmonary resuscitation. Still, there is a potential for knowledge and skill deterioration if the modality is not used regularly. In the absence of clinical practice, continuing education has been shown to be a valuable method of knowledge transfer and retention [14].

These findings may suggest a need to include information about the theory and concepts related to cupping therapy within athletic training curriculums. In the event that this proves difficult for athletic training education programs, continuing education programming should be considered for knowledge transfer of the definition, modes of action, indications, and contraindications of cupping therapy. When these continuing education presentations are created, they should be assessed and reassessed to make sure that they are effective and efficient at improving knowledge of cupping therapy among athletic trainers.

A possible limitation of this study was the number of participants. However, this is a similar limitation that other surveybased studies on athletic trainers have dealt with. That being said, this limitation may affect the generalizability of the results when looking to analyze across the profession [12-14]. Additionally, the response and completion rate was higher than some surveybased studies on athletic trainers [12]. The findings of this study support those of previous research that suggest a need for further research on the perceived knowledge of cupping therapy and therapeutic modalities in general among athletic trainers [12]. To the authors' knowledge, the first study to examine the perceived and actual knowledge of cupping therapy among athletic trainers from a specific region [12]. Future research should also be directed towards knowledge transfer and retention related to cupping therapy and other therapeutic modalities.

\section{Conclusion}

In conclusion, cupping therapy has grown in popularity as a treatment option among athletic trainers. The participants in this study appeared to demonstrate more actual knowledge of cupping therapy if they had a previous history of education on the topic. This demonstrates the need for education on treatment tools and techniques that are frequently used by athletic trainers. Given that continuing education has been suggested as a means of knowledge acquisition and retention, clinicians might benefit from creation of continuing education programming on cupping therapy.

\section{References}

1. Bridgett R, Mas D, Prac C, Klose P, Duffield R, et al. (2018) Effects of cupping therapy in amateur and professional athletes: Systematic review of randomized controlled trials. The Journal of Alternative and Complementary Medicine 24(3): 208-219.

2. Cage SA, Warner BJ, Gallegos DM, Sims-Koenig K (2020) Effects of cupping therapy on Lower Quarter Y-Balance Test scores in collegiate baseball players. Research \& Investigation in Sports Medicine 6(1): 466-468. 
3. Arce-Esquivel A, Warner B, Gallegos D, Cage SA (2017) Effect of dry cupping therapy on vascular function among young individuals. International Journal of Health Sciences 5(3): 10-15.

4. Cao H, Li X, Yan X, Wang N, Bensoussan A (2014) Cupping therapy for acute and chronic pain management: A systematic review of randomized clinical trials. Journal of Traditional Chinese Medical Sciences 2(1): 49-61.

5. Futterman M (2016) Michael Phelps leads Rio cupping craze. The Wall Street Journal.

6. Lyons K (2016) Interest in cupping therapy spikes after Michael Phelps gold win. The Guardian.

7. Cao H, Li X, Liu J (2012) An updated review of the efficacy of cupping therapy. PLos ONE 7(2): e31793.

8. Cage SA, Warner BJ, Gallegos DM (2020) Effect of cupping therapy on skin surface temperature in healthy individuals. Journal of Sports Medicine and Allied Health Sciences 5(3).

9. Chi L, Lin L, Chen C, Wang S, Lai H, et al. (2016) The effectiveness of cupping therapy on relieving chronic neck and shoulder pain: A randomized controlled trial. Evidence-Based Complementary and Alternative Medicine.
10. Liu W, Piao S, Meng X, Wei L (2013) Effects of cupping on blood flow under the skin of back in healthy human. World Journal of Acupuncture-Moxibustion 23(3): 50-52.

11. Lowe D (2017) Cupping therapy: An analysis of the effects of suction on the skin and possible influence on human health. Complimentary Therapies in Clinical Practice 29: 162-168.

12. Cage SA, Warner BJ, Gallegos DM, Winkelmann ZK (2020) Athletic trainers' perceived and actual knowledge of cupping therapy concepts. Journal of Sports Medicine and Allied Health Sciences 5(3).

13. Yang CW, Yen ZS, McGowan JE, Chen HC, Chiang WC, et al (2012 A systematic review of retention of adult advanced life support knowledge and skills in healthcare providers. Resuscitation 83(9): 1055-1060.

14. Schellhase K, Plant J, Rothschild C (2015) Collegiate athletic trainers' perceived and actual knowledge of therapeutic ultrasound concepts. International Journal of Athletic Therapy and Training 20(5): 43-53.

For possible submissions Click below: 